\title{
THE PROPERTIES OF A DOLOMITE BED OF \\ A RANGE OF PARTICLE SIZES AND SHAPES \\ AT MINIMUM FLUIDIZATION
}

by

S. C. Saxena and G. J. Vogel

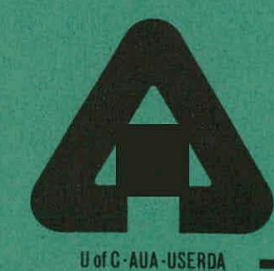

ARGONNE NATIONAL LABORATORY, ARGONNE, ILLINOIS

Prepared for the U. S. ENERGY RESEARCH

AND DEVELOPMENT ADMINISTRATION under Contract W-31-109-Eng-38 


\section{DISCLAIMER}

This report was prepared as an account of work sponsored by an agency of the United States Government. Neither the United States Government nor any agency Thereof, nor any of their employees, makes any warranty, express or implied, or assumes any legal liability or responsibility for the accuracy, completeness, or usefulness of any information, apparatus, product, or process disclosed, or represents that its use would not infringe privately owned rights. Reference herein to any specific commercial product, process, or service by trade name, trademark, manufacturer, or otherwise does not necessarily constitute or imply its endorsement, recommendation, or favoring by the United States Government or any agency thereof. The views and opinions of authors expressed herein do not necessarily state or reflect those of the United States Government or any agency thereof. 


\section{DISCLAIMER}

Portions of this document may be illegible in electronic image products. Images are produced from the best available original document. 
The facilities of Argonne National Laboratory are owned by the United States Government. Under the terms of a contract (W-31-109-Eng-38) between the U. S. Energy Research and Development Administration, Argonne Universities Association and The University of Chicago, the University employs the staff and operates the Laboratory in accordance with policies and programs formulated, approved and reviewed by the Association.

\section{MEMBERS OF ARGONNE UNIVERSITIES ASSOCIATION}

The University of Arizona

Carnegie-Mellon University

Case Western Reserve University

The University of Chicago

University of Cincinnati

Illinois Institute of Technology

University of Illinois

Indiana University

Iowa State University

The University of Iowa
Kansas State University

The University of Kansas

Loyola University

Marquette University

Michigan State University

The University of Michigan

University of Minnesota

University of Missouri

Northwestern University

University of Notre Dame
The Ohio State University

Ohio University

The Pennsylvania State University

Purdue University

Saint Louis University

Southern Illinois University

The University of Texas at Austin

Washington University

Wayne State University

The University of Wisconsin

NOTICE

This report was prepared as an account of work sponsored by the United States Government. Neither the United States nor the United States Energy Research and Development Administration, nor any of their employees, nor any of their contractors, subcontractors, or their employees, makes any warranty, express or implied, or assumes any legal liability or responsibility for the accuracy, completeness or usefulness of any information, apparatus, product or process disclosed, or represents that its use would not infringe privately-owned rights. Mention of commercial products, their manufacturers, or their suppliers in this publication does not imply or connote approval or disapproval of the product by Argonne National Laboratory or the U. S. Energy Research and Development Administration.

Printed in the United States of America Available from

National Technical Information Service

U. S. Department of Commerce 5285 Port Royal Road

Springfield, Virginia 22161

Price: Printed Copy $\$ 4.00$; Microfiche $\$ 2.25$ 
ANL/ES-CEN-1012

Coal Conversion and Utilization-Direct Combustion of Coal (UC-90e)

ARGONNE NATIONAL LABORATORY

9700 South Cass Avenue

Argonne, Illinois 60439

THE PROPERTIES OF A DOLOMITE BED OF A RANGE OF PARTICLE SIZES AND SHAPES

AT MINIMUM FLUIDIZATION

by

S. C. Saxena* and G. J. Vogel

Chemical Engineering Division

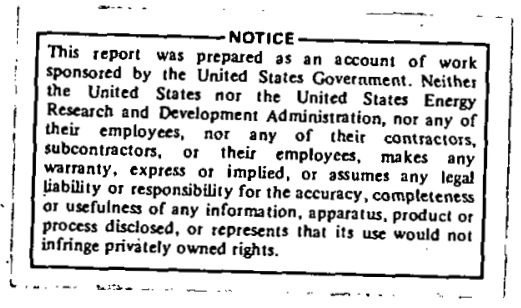

September 1975

*Present address: Vepartment of Energy Engineering, University of Illinois, Chicago, Illinots 60680 . 


\section{THIS PAGE}

\section{WAS INTENTIONALLY \\ LEFT BLANK}


TABLE OF CONTENTS

Page

NOMENCLATURE ........................... . . v

ABSTRACT . . . . . . . . . . . . . . . . . . . . 1

Introduction .......................... 2

Experimentation ......................... 2

Correlation for Minimum Fluidization Velocity . . . . . . . . 6

Calculation of Minimum Fluidization Velocity . . . . . . . . 10

Quality of Fluidization ................ . 16

CONCLUSIONS . . . . . . . . . . . . . . . . . . . 17

ACKNOWLEDGMENTS . . . . . . . . . . . . . . . . 17

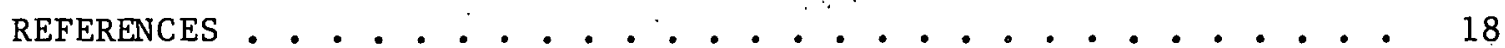




\section{LIST OF FIGURES}

№.

Title

$\underline{\text { Page }}$

1. The detailed drawing of the ANL 6-in.-dia, pressurized, fluidized-bed reactor . . . . . . . . . . . .

2. A correlation plot for particulate fluidization .....

\section{LIST OF TABLES}

No.

Title

$\underline{\text { Page }}$

1. Particle-size distribution of partially sulfated dolomite bed material before and the seven fluidization runs. . . . . . . . . . . . . . . . .

2. Experimental values of $u_{m f}, L_{m f}, \bar{\varepsilon}_{m f}, \operatorname{Re} p, m f$, and $\bar{\phi}_{s}$, at various temperatures and pressures . ........ .

3. Experimental and calculated values of minimum fluidization velocity . . . . . . . . . . . . .

4. Demonstration of the validity for equation 21 . . . . . 

A,

$\mathrm{Fr}_{\mathrm{mf}}$, Froude number at minimum fluidization as defined by equation 28,

g, multiparticle system,

the drag force acting on the particle when situated in an infinite expanse of fluid,

acceleration due to gravity.

conversion factor,

bed height,

bed height at minimum fluidization,

pressure drop across the fluidized bed,

maximum value of the pressure drop across lhe fluldized bed,

pressure drop across the bed at minimum fluidization,

tortuosicy factor,

fluidization factor defined by equation 6 ,

$\mathrm{Re}_{\mathrm{p}, \mathrm{mf}}$, particle Reynolds number at, minimum flutdization velocicy,
$\mathrm{Re}_{\mathrm{p}, \mathrm{mf}}^{\prime}$, modified Reynolds number defined by equation 19 ,

$S_{v}$, specific surface of the solid particles,

u, fluidizing gas velocity,

$u_{\mathrm{mf}}$, the minimum fluidization velocity,

w, weight of the fluidized bed,

$x$, weight fraction of particles in a specified size range,

z, a cross section factor.

Greek letters

$\varepsilon$, bed void fraction (voidage),

$\bar{\varepsilon}$ mean bed void fraction (mean voidage),

$\bar{\varepsilon}_{\mathrm{mf}}$, mean bed voidage at minimum fluidization,

$\mu$, viscosity of the fluidizing gas,

$\rho_{g}$, density of the fluidizing gas,

$\rho_{s}$, density of the solid particles,

$\phi_{S}$, sphericity of the solid particles,

$\bar{\phi}_{s}$. mean shape factor (sphericity) for the solid particles. 
THE PROPERTIES OF A DOLOMITE BED OF

A RANGE OF PARTICLE SIZES AND SHAPES

AT $\cdot$ MINIMUM FLUIDIZATION

by

S. C. Saxena and G. J. Vogel

\begin{abstract}
A two-phase model to describe the combustion of coal in a fluidized bed of dolomite would be critically influenced by the properties, at minimum fluidization, of bed materials of a range of particle sizes and shapes. To aid in developing the model, experiments have been performed with dolomite particles of a size distribution in the range of about 1410-88 $\mu \mathrm{m}$ in a 6-in.-diameter fluidized-bed reactor. The bed voidage at fluidization and the minimum fluidizing air velocities were determined as a function of temperature $\left(70-800^{\circ} \mathrm{F}\right)$ and pressure (26-121 psia). The experimental data suggest that, at a given temperature, the minimum fluidization velocity decreases with increasing pressure and that, at a given pressure, probably, it is independent of temperature. These data were correlated using the Ergun relation. The mean sphericity of the particles required in the Ergun correlation was determined from experimental pressure drop data at low Reynolds number.

Other methods often employed for predicting the minimum fluidization velocity of a bed of single-size spherical particles were examined with appropriate modifications for their applicability to a bed consisting of a wide range of particle sizes and shapes. Specific recommendations have been made as to the applicability of the different methods for calculating minimum fluidization velocities.
\end{abstract}


Coal can be burned in excess air in a pressurized fluidized-bed of dolomite or limestone particles. The latter react with the sulfur compounds formed as a result of coal combustion and thereby reduce environmental pollution. The efficiency for sulfur retention in this process and adequate mathematical modeling appropriate for its scaleup demand, among other things, the proper understanding of the characteristics of a fluidized bed consisting of a wide range of particle sizes and shapes.

The results of a series of fluidization experiments performed in the ANL, 6-in.-dia, fluidized-bed reactor (normally used as a combustor) in the temperature and pressure ranges of $70-800^{\circ} \mathrm{F}$ and $26-121$ psia are reported. In particular, the bed voidage at fluidization, the mean spherictty of the particles, and the minimum velocities were determined. Some comments are also made concerning the quality of fluidization of a bed of a range of parricle slzes and shapes. Theoe reeults are correlated on the basis of the Ergun relatlun.' Other methodo available in the 1it.erature and often employed for predicting the minimum fluidization velocity of a bed of single-size sphericul particles are examined here for their applicability to a bed of a range of particle sizes and shapes. Knowledge of the minimum fluidization velocity facilitates the modeling of the reaction kinetics of a fluidized-bed reactor since it permits the determination of the gas in the bubble phase as an excess over that required for minimum fluidization.

\section{Experimentation}

The experiments were performed on the ANL bench-scale equipment designed for operation at pressures up to $10 \mathrm{~atm}$. It consists of a fluidized-bed reactor (Fig. 1), a compressor for supplying fluidizingcombustion air, a preheater for this air, coal and additive feeders (for use in combustion runs), and an ott-gas system. The latter consiats of two cyclones, filters, gas sampling equipment, and a pressure letdown valve. The system is thoroughly instrumented and 15 eyuipped with an automatic data-logging system. The reactor consists of a 6-in.-dia stainless steel pipe, $11 \mathrm{ft}$ long. The exterior of the pipe is wrapped with electrical heaters to heat the bed from room temperature to a desired temperature and up to the coal ignition temperature at the start of a coal combustion experiment. Also wrapped around thie eurface are external cooling coils to cool the bed during coal combustion. Additional cooling is provided by hairpin coils immersed in the fluidized bed. In these experiments, with combustion absent, no cooling of the bed was required. In this work, the bed was charged with a known amount of dolomite and then was operated as a batch reactor. A marimun bed height of 36 in. was maintained in the reactor by use of an internal overflow pipe. Pressure taps installed in the reactor permitted measurements of pressure drops acruss the entire bed, as well as across two points ( $6 \mathrm{in.}$ apart) in the bed. From these data, the height of the bed can be determined as a function of the fluidizing air velocity. 


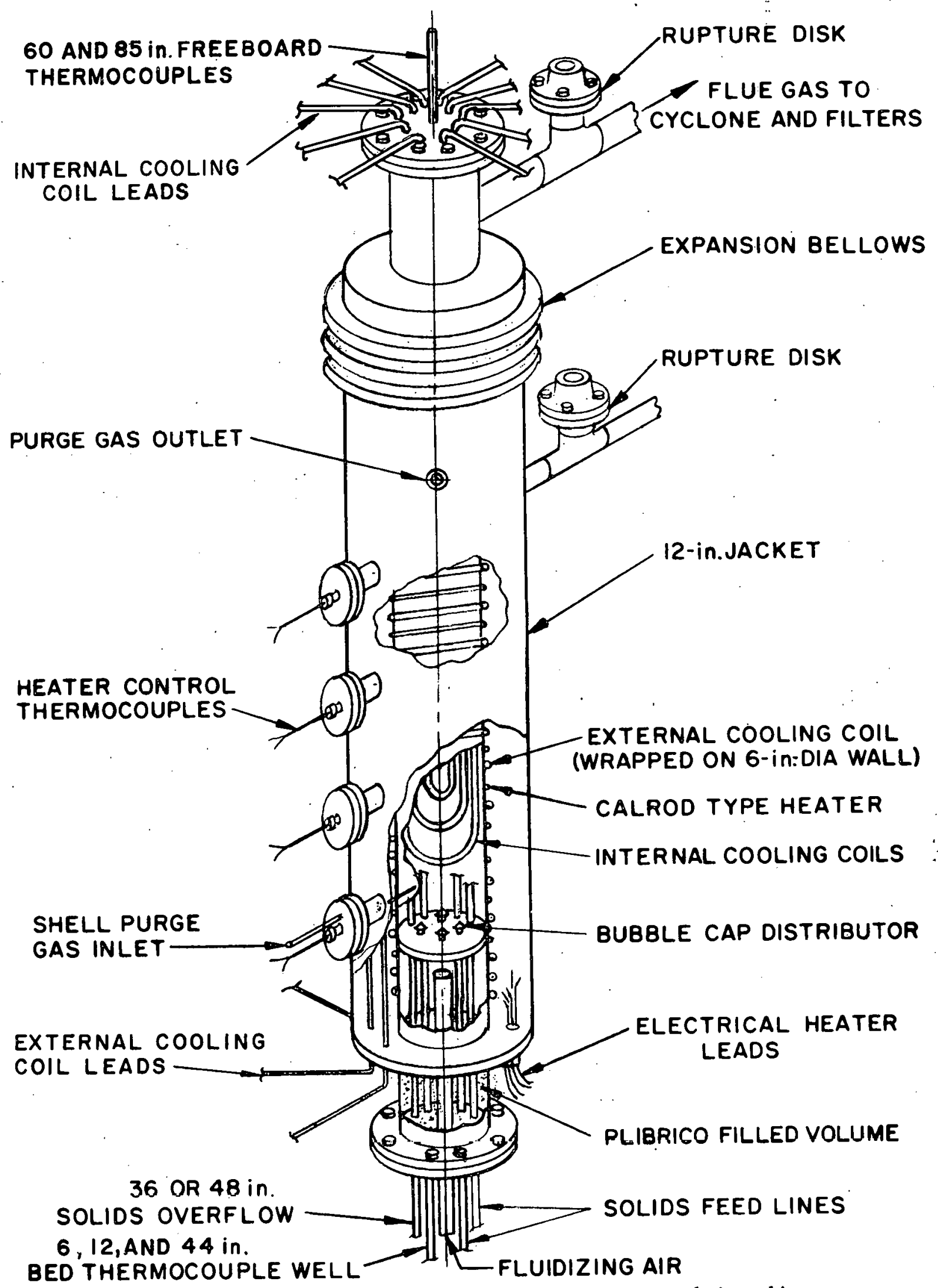

Fig. 1. The detailed drawing of the ANL 6-in.-dia, pressurized, fluidized-bed reactor. 
A knowledge of the dependence of the pressure drop across the bed, $\Delta \mathrm{P}$, on the gas velocity, $\mathrm{u}$, yields information on the structure of a fixed or fluidized bed. For small values of $u, \Delta P$ is proportional to the gas velocity. As $u$ increases, $\Delta \mathrm{P}$ increases until u reaches the value. $\mathrm{u}_{\mathrm{mf}}$, the minimum fluidization velocity. At this point, $\Delta \mathrm{P}$ attains its maximum value, $\Delta \mathrm{P}_{\max }=\mathrm{W} / \mathrm{A}$. Here $\mathrm{W}$ is the weight of the bed and $\mathrm{A}$ is the effective cross-sectional area. As the gas velocity is increased beyond $u_{\mathrm{mf}}$, gas bubbles form. Because a bubbling bed can easily deform, the pressure drop can remain constant over a range of $u$ values above $u_{\mathrm{mf}}$. However, under certain conditions the bubbles grow by coalescence to a diameter almost equal to the bed diameter before they escape from the bed and large pressure fluctuations occur. Also, channeling may occur in the bed and a large fraction of the bed remains unfluidized, in which case the $\Delta \mathrm{P}_{\max }$ is less than $\mathrm{W} / \mathrm{A}$. Furthermore, anomalous pressure drops may be observed if circulation patterns are set up within the bed and cause the energy to be lost by friction among the solid bed particles and between the particles and the walls containing the fluidized bed. It is clear, therefore, that a plot of $\Delta \mathrm{P}$ versus $\mathrm{u}$ is useful indicator. of the nature or quality of tluidization. Fluldizalion experimente made to gain insight into the quality of fluidization and to determine the minimum fluidizing veloclty dre liext reported.

The reactor was charged with $14.9 \mathrm{~kg}$ of partially sulfated dolomite. The particle size distribution as obtained by sieve analysis is given in Table 1 , as is the mass-welghted average particle diameter, $\overrightarrow{\mathrm{d}}_{\mathrm{p}}$, computed from the following relation:

$$
\overline{\mathrm{d}}_{\mathrm{p}}=\frac{1}{\sum_{i}\left(\mathrm{x} / \mathrm{d}_{\mathrm{p}}\right) i}
$$

Here $\mathrm{x}$ is the welght fraction of particles in a size range $j$ of diameter $d_{p}$. Seven fluidization experiments were conducted with this bed, using various combinations of temperature $\left(70-800^{\circ} \mathrm{F}\right)$ and pressure (26-121 psia). Pressure drop measurements were obtained for both increasing and decreasing gas velocities. For each experiment, a straight line was drawn from the origin through the $\Delta \mathrm{P}$ points that represented decreasing values of $u$. The intersection of this line with the line representing W/A was regarded as characterizing the minimum fluldizdilun velocity. The experimental values of $u_{m f}$ are listed in Table 2. On the whole, W/A was found to be a good measure of $\Delta \mathrm{P}_{\max }$ if the range of uncertainties associated with the various measurements was taken into consideration. Aiso, a detectable hysteresis effect in room temperature experiments was found, $i . e .$, the $\Delta \mathrm{P}$ values for a specific $\mathrm{u}$ were larger when the gas velocity was being increased than when the velocity was being decreased. Significantly, this effect became negligible when the pressure and/or temperature was increased. Also, a "hump" in the plot of $\Delta \mathrm{P}$ versus $\mathrm{u}$ that was observed in the data pertaining to $70^{\circ} \mathrm{F}$ and 30 psia disappeared for runs at higher pressures and/or temperatures. In almost all cases, the data for $\Delta P$ are reasonably cunsistent for valucs. of $\mathbf{u} \leq \mathbf{u}_{\mathrm{m} r}$, but at 1 .arger values of $\mathrm{u}$, an appreciable scatter in $\Delta \mathrm{P}$ values is evident. In some cases, the 
Table 1. Particle-size distribution of partially sulfated dolomite bed material before and after the seven fluidization runs.

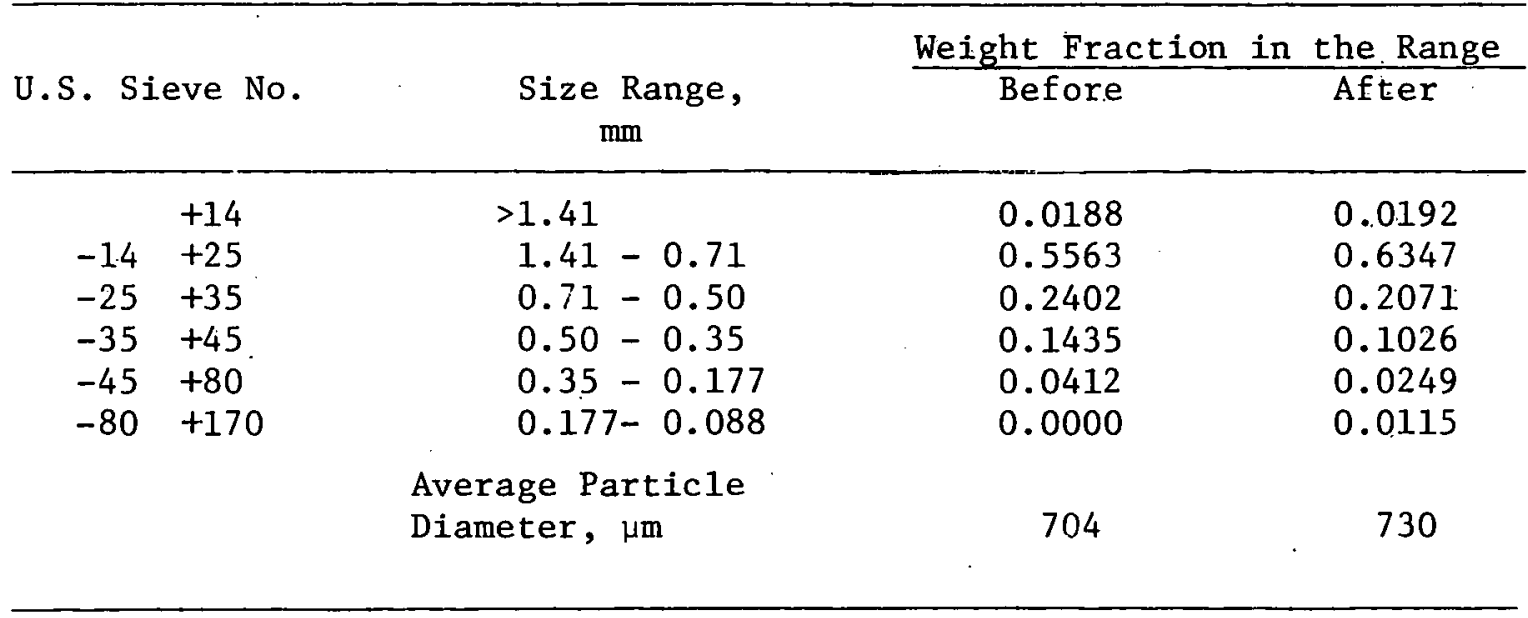

Table 2. Experimental values of $u_{m f}, L_{m f}, \bar{\varepsilon}_{m f}, \operatorname{Re} p, m f$, and $\bar{\phi}_{s}$, at various temperatures and pressures.

\begin{tabular}{|c|c|c|c|c|c|c|c|}
\hline $\begin{array}{c}\text { Experiment } \\
\text { No. }\end{array}$ & $\begin{array}{l}\text { Temp, } \\
{ }^{\circ} \mathrm{F}\end{array}$ & $\begin{array}{c}\text { Pressure, } \\
\text { psia }\end{array}$ & $\begin{array}{c}u_{m f}, \\
f t / s e c\end{array}$ & $\begin{array}{c}\mathrm{L}_{\mathrm{mf}}, \\
\mathrm{ft}\end{array}$ & $\bar{\varepsilon}_{\mathrm{mf}}$ & $\mathrm{Re}_{\mathrm{p}, \mathrm{mf}}$ & $\bar{\phi}_{\mathbf{S}}$ \\
\hline 2 & 70 & 30 & 1.18 & 2.96 & 0.631 & 36 & -- \\
\hline 3 & 70 & 121 & 0.755 & 3.25 & 0.662 & 93 & -- \\
\hline 4 & 70 & 72 & 0.91 & 3.25 & 0.663 & 70 & -- \\
\hline 5 & $510+10$ & 26 & 1.18 & 3.18 & 0.657 & 12 & 0.3635 \\
\hline 6 & $480 \mp 25$ & 120 & 0.77 & 3.20 & 0.659 & 33 & -- \\
\hline 7 & $720 \mp 25$ & 120 & 0.765 & 3.00 & 0.636 & 23 & -- \\
\hline 8 & $800 \mp 25$ & 73 & 0.85 & 3.00 & 0.636 & 14 & 0.3634 \\
\hline Mean & -- & - & -- & - & 0.65 & -- & 0.364 \\
\hline
\end{tabular}

scarcer cannot be explained by the error limits of our measurements. These plots suggest that the observed response is not always characteristic of a bubbling bed; the large fluctuations may indicated slugging in the bed.

After the series of runs was completed, the bed was drained and weighed; its weight was on 1 y $4.5 \%$ less than its initial weight. No significant amount of material was found in the primary cyclone. Sieve analysis of a sample from the drained bed yielded the particle-size distribuction reported in the fourth column of Table 1 . The average particle diameter for the material originally fed, computed from equation 1 , was found to be $704 \mu \mathrm{m}$. Since the average particle diameter after 
the runs was $730 \mu \mathrm{m}$, we regard the weight of the bed as constant for all. runs. Also, the dolomite bed particles were found to have a smooth size distribution; consequently, the onset of fluidization and the plots of $\Delta \mathrm{P}$ versus $\mathrm{u}$ may be interpreted in terms of a bed of uniform size particles of diameter $\overline{\mathrm{d}}_{\mathrm{p}}$. In the calculations described later, a mean value of $717 \mu \mathrm{m}$ is used for $\overrightarrow{\mathrm{d}}_{\mathrm{p}}$.

The experimental $\mathrm{u}_{\mathrm{mf}}$ values reported in Table 2 indicate that at a given temperature, $u_{\mathrm{mf}}$ decreases with increasing pressure. These data also suggest that at a pressure of $8 \mathrm{~atm}, u_{\mathrm{mf}}$ is almost independent of temperature in the range $70-720^{\circ} \mathrm{F}$. These results also indicate that at a pressure of $8 \mathrm{~atm}, u_{\mathrm{mf}}$ is almost independent of temperature and that the same conclusion is valid at pressures of 2 and 5 atm. Thus in the pressure range of current measurements, $u_{m f}$ appears to be almost independent of temperature. Also listed in this table are the values of the height of the fluidized bed at minimum fluidization, $\mathrm{L}_{\mathrm{mf}}$, as obtainod from pressure drop measurements.

Correlation for Minimum Fluidization Velocity

Correlation of these observed values of $u_{m f}, L_{m f}$, and $\Delta P_{m f}$ as a function of temperature and pressure on the basis of Ergun's correlation ${ }^{1}$ for the pressure drop across a fixed and fluidized bed was attempted.

The theoretical basis of Ergun's correlation is based on works which are reviewed by Carman, ${ }^{2}$ and the numerical constanls and gencral form of the correlation are substantiated by a large :body of experimental work of Chilton and Colburn, ${ }^{3}$ Leva et al. ${ }^{4,5}$ Ergun and Orning, ${ }^{6}$ and others. The experiments in almost all cases were performed on particles of a single size or a narrow size distribution. The Ergun correlation for a fixed bed based on data mostly ubtained at room temperature and atmospheric pressure is as follows:

$$
\frac{\Delta \mathrm{Pg}_{\mathrm{c}}}{\mathrm{L}}=150 \frac{(1-\bar{\varepsilon})^{2} \mu \mathrm{u}}{\bar{\varepsilon}^{3} \overline{\mathrm{D}}_{\mathrm{p}}^{2}}+1.75 \frac{(1-\bar{\varepsilon}) \rho_{\mathrm{g}} \mathrm{u}^{2}}{\bar{\varepsilon}^{3} \overline{\mathrm{D}}_{\mathrm{p}}}
$$

Here $\Delta P$ is the pressure drop across a bed of helght, $L$; $\bar{\varepsilon}$ is the mean void fraction (voldage); $u$ is the superficial gas velocity; $\mu$ is the gas viscosity; $\rho \mathrm{g}$ is the gas density; $\mathrm{g}_{\mathrm{c}}$ is the conversion factor and is equal to $980 \mathrm{~g} \mathrm{~cm} /(\mathrm{g}-\mathrm{wt})\left(\mathrm{sec}^{2}\right)$; and $\overline{\mathrm{V}}_{\mathrm{p}}$, the meall particlc diamoter, is defined in terms of $\mathrm{S}_{\mathrm{v}}$, the specific surface of the solid particles (i.e., the solid particle surface ared per unit volume of the solid) as lollows:

$$
\bar{D}_{p}=\left(6 / s_{v}\right)=\bar{\phi}_{s} \bar{d}_{p}
$$

Equation 3 , involving the mean shape factor, $\bar{\phi}_{S}$, and the mean particle diameter, $\bar{d}_{p}$, defined by equation 1 , is used here to interpret the 
behavior of a bed composed of nonspherical particles of a wide size distribution. The weight fraction in the size interval of average diameter, $d_{p}$, is obtained in this work by sieve analysis. If $d_{p}$ is the diameter of the sphere having the same volume as that of the particle, the shape factor, $\phi_{S}$, would represent the sphericity of the particle.

Equation 2 may be applied ${ }^{6,7}$ to a fluidized bed at minimum fluidization as follows:

$$
\frac{\Delta \mathrm{P}_{\mathrm{mf}} \mathrm{g}_{\mathrm{c}}}{\mathrm{L}_{\mathrm{mf}}}=150 \frac{\left(1-\bar{\varepsilon}_{\mathrm{mf}}\right)^{2} \mu \mathrm{u}_{\mathrm{mf}}}{\bar{\varepsilon}_{\mathrm{mf}}\left(\bar{\phi}_{\mathrm{s}} \overline{\mathrm{d}}_{\mathrm{p}}\right)^{2}}+1.75 \frac{\left(1-\bar{\varepsilon}_{\mathrm{mf}}\right) \rho_{\mathrm{g}} \mathrm{g}_{\mathrm{mf}}{ }^{2}}{\bar{\varepsilon}_{\mathrm{mf}}^{3}\left(\bar{\phi}_{\mathrm{s}} \overline{\mathrm{d}}_{\mathrm{p}}\right)}
$$

where the subscript mf signifies minimum fluidization. Furthermore, $\Delta \mathrm{P}_{\mathrm{mf}}$ is equal to the buoyant weight of the dolomite particles per unit area:

$$
\Delta \mathrm{P}_{m f} g_{c}=\left(\rho_{s}-\rho_{g}\right)\left(1-\bar{\varepsilon}_{m f}\right) L_{m f} g
$$

where $\rho_{\mathbf{s}}$ is the solid particle density and $g$ is the acceleration due to gravity.

The plots of $\Delta \mathrm{P}$ versus $\mathrm{u}$ (not included here) indicated that the quantity, $Q$, at minimum fluidization, defined as

$$
\mathrm{Q}=\Delta \mathrm{P}_{\mathrm{mf}}(\mathrm{A} / \mathrm{W})
$$

is unity for all seven experiments and that therefore

$$
\Delta \mathrm{P}_{\mathrm{mf}}=\mathrm{W} / \mathrm{A}
$$

The density of fresh and unsulfated dolomite particles was experimentally determined to be $2.749+0.004 \mathrm{~g} / \mathrm{cc}$. The density was determined by the weight loss of a known amount of dolomite in water. A trace of surfactant was added to the water prior to the determination. Equations 5 and 7 are employed to compute $\bar{\varepsilon}_{\mathrm{mf}}$, and these values of $\bar{\varepsilon}_{\mathrm{mf}}$ are reported in Table 2 .

It is clear that, for the range of particle sizes and operating conditions of temperature and pressure employed_in the experiments, the use of the mean value of 0.65 for bed voidage, $\bar{\varepsilon}_{\mathrm{mf}}$, at minimum fluidizing conditions is adequate for calculations. The voidage of a mixture of particles with a wide size distribution is difficult to estimate because the fines can fit into the voids between the large particles and thus decrease voidage. On the other hand, it has been shown ${ }^{2}, 8$ that the particles pack more loosely near the walls as a result of air velocity near the walls differing from that in the middle section. The latter effect increases as the ratio of the particle diameter to the bed diameter increases. In our bed, additional enhancement of this effect is a 
result of the presence of hairpin cooling coils. If segregation of the particles occurs, the voidage can vary appreciably along the height of the bed as a result of the larger particles being packed tighter at the bottom of the bed and more and more light particles populating the upper regions of the bed. This would result in the voidage increasing with height and call into question the validity of the concept of mean bed porosity (voidage) in fluidized-bed operations involving a wide range of particle sizes.

The particle Reynolds number, ${ }^{2}{ }_{p}$, is defined as

$$
\operatorname{Re}_{p}=\vec{d}_{p} \rho g u / \mu
$$

When $\mathrm{Re}_{\mathrm{p}}$ is smaller than 20 , the rightmost term of equation 4, which represents the kinetic energy losses, is negligibly small. Under such conditions, the observed pressure drop is almost completely accounted for by the viscous effect, so that at minimum fluidization,

$$
\frac{\Delta \mathrm{P}_{\mathrm{mg}} \mathrm{g}_{\mathrm{c}}}{\mathrm{L}_{\mathrm{mf}}}=150 \frac{\left(1-\bar{\varepsilon}_{\mathrm{mf}}\right)^{2} \mu \mathrm{u}_{\mathrm{mf}}}{\varepsilon_{\mathrm{mf}}\left(\bar{\phi}_{\mathrm{s}} \overline{\mathrm{d}}_{\mathrm{p}}\right)^{2}}
$$

as long as

$$
\operatorname{Re}_{\mathrm{p}, \mathrm{mf}}=\frac{\overline{\mathrm{d}}_{\mathrm{p}} \rho_{\mathrm{g}}{ }^{\mathrm{u}} \mathrm{mf}}{\mu}<20
$$

The Reynolds numbers at minimum fluidization velocity, $\mathrm{Re}_{\mathrm{p}, \mathrm{mf}}$, computed for the various experiments are listed in Table 2. For experiments 5 and 8 , the condition of equation 10 is satisfied. Equation 9, in conjunction with equation 7 , is employed to compule the mean particle sphericity, $\bar{\phi}_{S}$, and the results are given in the eighth column of Table 2. The agreement between the two values is fortuitously good, but their apparent small magnitudes are somewhat puzzling at first sight. The calculated values of particle sphericity, $\phi_{3}$, from microscopic measurements summarized by Carman ${ }^{2}$ suggest that such low values are characteristic of fibers and flakes. The low values of $\bar{\phi}_{S}$ are due to the use of $\bar{d}_{p}$ values as determined by sieve analysis. To illustrate the point, let us assume that the value of $\bar{\phi}_{s}$ is 0.6 . Then on the basis of our experimental value for $\bar{\phi}_{S}$, the diameters determined by screen analysis must be multiplied by about 0.61 to obtain the diameters of the equivalent spheres that would have the same volume as the particles. These numerical figures would agree with the exact calculations iff the dolomite particles should have approximately a disk shape with a thickness one-third of the disk radius. Further, it must be kept in mind that the accuracy of the correlation of equation 2, even for well-behaved packed beds, is estimated to be $\pm 25 \%$. We thus regard the mean shape-size factor, $\bar{\phi}_{s} \bar{d}_{p}$, as a semiempirical adjustable parameter, and this concept should prove useful if equation 4 emerges as a successful correlating relations for $u_{\mathrm{mf}}$. This cuncept is evaluated below. 
The mean fluidizing velocities computed for the operating conditions corresponding to experiments $2,3,4,6$, and 8 from equation 4 are 1 isted in Table 3, column 5. These calculated values agree with the directly measured values (listed in column 4 of Table 3), within an average absolute deviation and a maximum deviation of 2.7 and 4.5 percent, respectively. This agreement is regarded as satisfactory because the accuracy of the experimental $u_{\mathrm{mf}}$ values is estimated to be \pm 5 percent. It also follows from this good agreement between the two sets of $u_{m f}$ values that similar good agreement would probably be obtained for $\bar{\phi}_{S}$, if the data on the remaining runs (all at $\operatorname{Re}_{\mathrm{p}, \mathrm{mf}}>20$ ) were to be employed. The point to be stressed is the success of the Ergun correlation with this semi-empirically determined shape-size factor in quantitatively predicting the temperature and pressure dependence of $u_{m f}$. Thus, experimental trends, one indicating that at a given temperature, $u_{m f}$ decreases with increasing pressure and the other that at a given pressure, $u_{m f}$ is almost independent of temperature, are quantitatively confirmed by the Ergun relation. The interpolation within the range of the operating variables, as well as a modest amount of extrapolation, seems warranted and reliable enough for engineering design calculations.

Table 3. Experimental and calculated values of minimum fluidization velocity

\begin{tabular}{ccccccc}
\hline \multirow{2}{*}{$\begin{array}{c}\text { Experiment } \\
\text { No. }\end{array}$} & $\begin{array}{c}\text { Temp } \\
{ }^{\circ} \mathrm{C}\end{array}$ & $\begin{array}{c}\text { Pressure } \\
\text { atm }\end{array}$ & Expt1. & \multicolumn{3}{c}{ Calculated } \\
\cline { 5 - 7 } & 20 & 2.04 & 36.0 & 37.7 & 31.1 & 45.6 \\
3 & 20 & 8.23 & 23.0 & 23.4 & 20.5 & 45.5 \\
4 & 20 & 4.90 & 27.7 & 27.3 & 24.0 & 45.5 \\
5 & $265 \pm 5$ & 1.77 & 36.0 & -- & 26.4 & 30.0 \\
6 & $240 \pm 15$ & 8.16 & 23.5 & 24.1 & 22.9 & 30.5 \\
7 & $380 \pm 30$ & 8.16 & 23.3 & 24.4 & 20.4 & 26.3 \\
8 & $425 \pm 15$ & 4.97 & 25.9 & -15 & 21.5 & 25.2 \\
\hline
\end{tabular}

In the above treatment we have assumed that there is no flocculation or clustering of small particles. ${ }^{9}$ However, if flocculation or clustering occurs, $\overline{\mathrm{d}}_{\mathrm{p}}$ will increase and this will lead to smaller pressure drops on the basis of equation 4. A smaller pressure drop will also result with any increase in $\bar{\phi}_{S}$. The Ergun relation can be broadened by 
adding a third term on the right-hand side of equation 4. This term should include the influence of hairpin cooling coils, thermowells, and the walls of the reactor, because these present a different type of surface to the fluid than do the bed particles. ${ }^{8}$ Ergun $^{1}$ noted the inapplicability of equation 4 to systems involving mixtures of different size particles when the ratio of tube diameter to average particle size is less than 10. For the larger particles in our feed, the configuration of our reactor (with cooling coils immersed in the bed) simulate such conditions. However, the cooling coils and the thermowells located close to the reactor walls occupy only about 15 percent of the reactor cross section. Thus, apparently only a small portion, at most, of any probable discrepancy can be attributed to this source. The view of treating $\bar{\phi}_{s}$ as an adjustable parameter in the Ergun relation appears to be expedient at the present time.

\section{Calculation of Minimum Fluidization Velocity}

Our experimentally determined values of minimum fluidization velocity will now be discussed in the light of various procedures described in the literature for their prediction and correlation.

The various correlation methods developed for minimum fluidization velocity and hence appropriate for its calculation are described by Leva ${ }^{10}$ and Frantz. ${ }^{11}$ Some of the more recent correlations are due to Narsimhan, 12 Frantz, 13 and Wen and Yu. ${ }^{14,15}$ of these methods, the expressions given by Narsimhan ${ }^{12}$ and Wen and $\mathrm{Yu}^{1{ }^{1}}$ are tested against sufficient experimental data and are consequently fairly reliable. For computing the minimum fluidization velocity for the operating conditfons of the series of seven runs described above, use of the expression of Wen and $\mathrm{Yu}^{14}$ is preferred because it is based on more realistic estimates $^{15}$ of minimum fluidization voidage and the particle shape factor.

By combining equations 4 and 5 , we get

$$
150 \frac{\left(1-\bar{\varepsilon}_{\mathrm{mf}}\right)^{2} \mu u_{\mathrm{mf}}}{\bar{\varepsilon}_{\mathrm{mf}}^{3}\left(\bar{\phi}_{\mathrm{s}} \overline{\mathrm{d}}_{\mathrm{p}}\right)^{2}}+1.75 \frac{\left(1-\bar{\varepsilon}_{\mathrm{mf}}\right) \rho_{\mathrm{g}} \mathrm{u}_{\mathrm{mf}}^{2}}{\bar{\varepsilon}_{\mathrm{mf}}^{3}\left(\bar{\phi}_{\mathrm{s}} \overline{\mathrm{d}}_{\mathrm{p}}\right)}-g\left(\rho_{\mathrm{s}}-\rho_{\mathrm{g}}\right)\left(1-\bar{\varepsilon}_{\mathrm{mf}}\right)=0
$$

Equation 11 can be rearranged by introducing the particle Reynolds number at minimum fluidization, Rep, mf, and the Gallleo number, Ga, so that

$$
150 \frac{\left(1-\bar{\varepsilon}_{\mathrm{mf}}\right)}{\bar{\phi}_{\mathrm{S}}^{2} \bar{\varepsilon}_{\mathrm{mf}}^{3}} \mathrm{Re}_{\mathrm{p}, \mathrm{wL}}+1.75 \frac{\mathrm{Re}_{\mathrm{p}, \mathrm{mf}}^{2}}{\bar{\phi} \bar{\varepsilon}_{\mathrm{mf}}^{3}}-\mathrm{Ga}=0
$$

where

$$
G a=\frac{\bar{d}_{p} \rho_{g}\left(\rho_{s}-\rho_{g}\right) g}{\mu^{2}}
$$


Wen and $\mathrm{Yu}^{14}$ suggested, on the basis of experimental data available in the literature, that the two groups of $\bar{\phi}_{s}$ and $\bar{\varepsilon}_{\mathrm{mf}}$ occurring in equation 12 be approximated by the following relations:

$$
\frac{\left(1-\bar{\varepsilon}_{\mathrm{mf}}\right)}{\bar{\phi}_{S}^{2} \bar{\varepsilon}_{\mathrm{mf}}^{3}}=11 \text { and } \frac{1}{\bar{\phi} \bar{\varepsilon}_{\mathrm{mf}}^{3}} \simeq 14
$$

Our experimental $\bar{\varepsilon}_{\mathrm{mf}}$ and $\bar{\phi}_{\mathrm{s}}$ values give, for the two groups of equation 14, the values of 9.6 and 10, respectively. The two sets of numerical values are only in fair agreement with each other, and it is interesting to examine the following simplified version of equation 12 obtained on the basis of equation 14 for predicting $u_{\mathrm{mf}}$ :

$$
u_{\mathrm{mf}}=\frac{\mu}{\overline{d_{p} \rho g}}\left\{\left[(33.7)^{2}+0.0408 \mathrm{Ga}\right]^{1 / 2}-33.7\right\}
$$

Values calculated by the use of equation 15 are given in column 6 of Table 3; it will be noticed that the relation of equation 15 consistently underestimates the values of $u_{\mathrm{mf}}$ by about 15 percent. This is to be regarded as satisfactory agreement since a statistical evaluation of equation 15 with 284 data points by Wen and $\mathrm{Yu}^{14}$ yielded a standard deviation of 34 percent and an average deviation of \pm 25 percent. However, this comparison of theory and experiment does emphasize the importance of using accurate $\bar{\varepsilon}_{\mathrm{mf}}$ and $\bar{\phi}_{\mathrm{S}}$ values in estimating $u_{\mathrm{mf}}$ based on equation 12 .

If $R_{p}, m f$ is less than twenty, the second term of equation 11 representing the kinetic energy losses is negligibly smaller than the first term referring to the viscous losses, and equation 11 simplifies to:

$$
u_{\mathrm{mf}}=\frac{\left(\bar{\phi}_{s} \bar{d}_{p}\right)^{2} g\left(\rho_{s}{ }^{-\rho_{g}}\right) \bar{\varepsilon}_{\mathrm{mf}}^{3}}{150 \mu\left(1-\bar{\varepsilon}_{\mathrm{mf}}\right)}
$$

Equation 16 in ronjunstion with equation 14 further simplified to the following:

$$
u_{m f}=\frac{\left(\bar{\phi}_{s} \bar{d}_{p}\right)^{2} g\left(\rho_{s}{ }^{-\rho_{g}}\right)}{1650 \mu}
$$

In our experiments, $R e_{p}$, mf ranges from 12 to 92 if $\bar{d}_{p}$ is based on the nominal apertures of the sieves used in the particle size analysis. In establishing the limit for equation 16 in terms of $R_{p}, m f$, the size dimension used was the diameter of an equivalent sphere that has the same volume as the actual particle. We may consequently expect only moderate success for equation 17 in correlating our measured $u_{m f}$ values. Values computed from equation 17 are reported in the seventh column of 
Table 3, and these values are generally larger than the experimental values given in the fourth column of this table. Alternative values for the numerical coefficient in equation 17 have been recommended. Davidson and Harrison 16 and Davies and Richardson ${ }^{17}$ recommended values of 1233 and 1282 , respectively. Such choices would further worsen the agreement between the computed and experimental values.

Another important feature to note concerning euqation 17 is its inability to reproduce the observed pressure and temperature dependencies of $\mathrm{u}_{\mathrm{mf}}$. Mii, Yoshida, and Kunii ${ }^{18}$ reported the inability of equation 16 to reproduce their experimentally determined $u_{\mathrm{mf}}$ values as a function of temperature in the range $20-800^{\circ} \mathrm{C}$; the calculated values were greater than the values they observed. Mii et $a l$. data pertain to graphite spheres of 0.20 to $0.40 \mathrm{~mm}$ diameter at ambient pressure. On the other hand, the work of Singh, Rigby, and Callcott, 19 who used silica sand with a mean particle size of $200 \mu \mathrm{m}$ in the temperature range $288-973^{\circ} \mathrm{K}$ at ambient pressure, confirms the appropriateness of equation 17 with a value of $1386 \pm 90$ for the numerical constant. The primary motivation of their work ${ }^{19}$ was to confirm the dependence of $u_{m f}$ on $\mu$ as given by equation 16 and equation 17 . Broughton 20 suggests the use of equation 17 with 1440 as the numerical coefficient for computing $u_{m f}$ with a maximum error ot $15 \%$. Broughton ${ }^{20}$ also explains why Mii et a . data $^{18}$ may be in error.

It follows from the above analysis that the application of equation 16 or equation 17 to a system at a pressure higher than ambient is inappropriate, though the majority of literature evidence supports their adequacy for representing the dependencies of $u_{m f}$ on temperature and viscosity of the fluidizing gas at ambient pressure and for 10w Reynolds number.

For a particle Reynolds number smaller than 5 , Leva ${ }^{2}$ has suggested a relation similar to that of equation 17 except that the numerical factor is replaced with $1429 \mathrm{Re}_{\mathrm{p}}^{0.063} \mathrm{~m}$. This correlation has been ex-

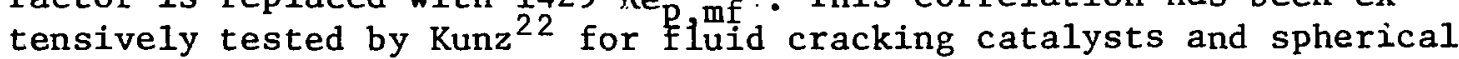
glass beads but is not employed here because it is only valid for systems characterized by very low Reynolds numbers.

The Ergun correlation at minimum fluidization as given by equation 4 may be rearranged in the following linear form:

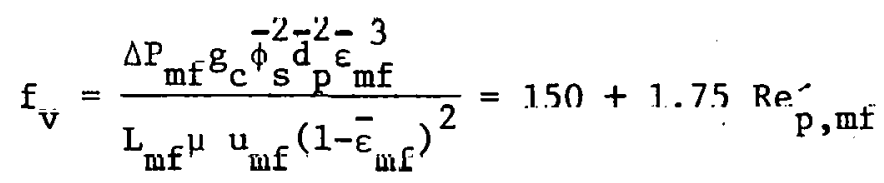

where

$$
\operatorname{Re}_{\mathrm{p}, \mathrm{mf}}^{\prime}=\frac{\bar{\phi}_{\mathrm{s}}}{\left(1-\bar{\varepsilon}_{\mathrm{mf}}\right)} \operatorname{Re}_{\mathrm{p}, \mathrm{mf}}
$$


Here $f_{v}$ is the viscous friction factor and is dimensionless. The modified Reynolds number $\operatorname{Re}_{\mathrm{p}}^{\prime}, \mathrm{mf}$, is defined in terms of (1) the Reynolds number given by equation $10,(2)$ the mean sphericity, $\bar{\phi}_{S}$, which is one for spherical particles, and (3) the mean bed voidage, $\bar{\varepsilon}_{\mathrm{mf}}$.

Hicks ${ }^{23}$ has shown that for spherical particles, the above relation of equation 18 is not in accordance with the observed pressure drop for $\mathrm{Re}_{\mathrm{p}, \mathrm{mf}}$ greater than 500. He recommends a nonlinear relation for $\mathrm{f}_{\mathrm{v}}$ in the range $300<\operatorname{Re}_{\mathrm{p}} /(1-\varepsilon)<60,000$. In our experiments with nonspherical $\left(\bar{\phi}_{S}=0.364\right)$ dolomite particles of a size range from slightly greater than 14 mesh (U.S. Sieve No.) to +170 , the maximum value of Re about 95. The validity of the linear relation of equation 18 in interpreting our experimental data is then in conformity with the findings of Hicks.

In contrast to the Ergun relation of equation 11 derived by consideration of pressure drop, Wen and $\mathrm{Yu}^{14}$ developed a correlation on the basis of drag force considerations. They found that the drag force, $\mathrm{F}_{\mathrm{k}}$, of a fluid acting on a single spherical particle in a multiparticle system is related by the following relation to the drag force, $F_{k s}$, of the same fluid on this particle when situated in an infinite expanse of fluid:

$$
\mathrm{F}_{\mathrm{k}}=\bar{\varepsilon}^{4.7} \mathrm{~F}_{\mathrm{ks}}
$$

Further, by assuming the validity of the above relation at minimum fluidization, Wen and $\mathrm{Yu}^{14}$ equated the drag and the buoyance forces acting on the particle with the gravitational force and derived a correlation that is valid for Reynolds numbers up to 1000 , particle diameters ranging from 0.001524 to $0.635 \mathrm{~cm}, \rho_{\mathrm{s}}$ from 1.06 to $11.25 \mathrm{~g} / \mathrm{cc}$, fluid density from 0.818 to $1.135 \mathrm{~g} / \mathrm{cc}$, and $\mu$ from 1.0 to 15.01 centipoise. This correlation, after modification to apply to a wide size range of nonspherical. particles, becomes:

$$
\bar{\varepsilon}_{\mathrm{mf}}^{4.7} \bar{\phi}_{\mathrm{s}}^{2} \mathrm{Ga}=18 \mathrm{Re}{ }_{\mathrm{p}, \mathrm{mf}}+2.70 \bar{\phi}_{\mathrm{s}}^{0.687}\left(\mathrm{Re}_{\mathrm{p}, \mathrm{mf}}\right)^{1.687}
$$

The validity of equation 21 was checked on the basis of results of the same series of seven runs for which data are reported in Table 3 , and the results given in Table 4 were obtained. The modified correlation is shown to be adequate by this comparison of theory and experiment, and the average absolute deviation of $9.4 \%$ is about the same as that found by Wen and Yu. ${ }^{14}$ This result also substantiates that the correlations obtained for $u_{\mathrm{mf}}$ on the basis of either pressure drop or drag forces for a wide range of nonspherical particles given similar results. A similar conclusion is derived by Wen and $\mathrm{Yu}^{14}$ for spherical particles of a moderate size range.

Zenz 24,25 generated plots of $\left(\operatorname{Re}_{\mathrm{p}} / \mathrm{C}_{\mathrm{D}}\right)^{1 / 3}$ versus $\left(\mathrm{C}_{\mathrm{D}} \operatorname{Re}_{\mathrm{p}}^{2}\right)^{1 / 3}$ as a function of bed voidage to describe particulate fluidization charac- 
Table 4. Demonstration of the validity for equation 21.

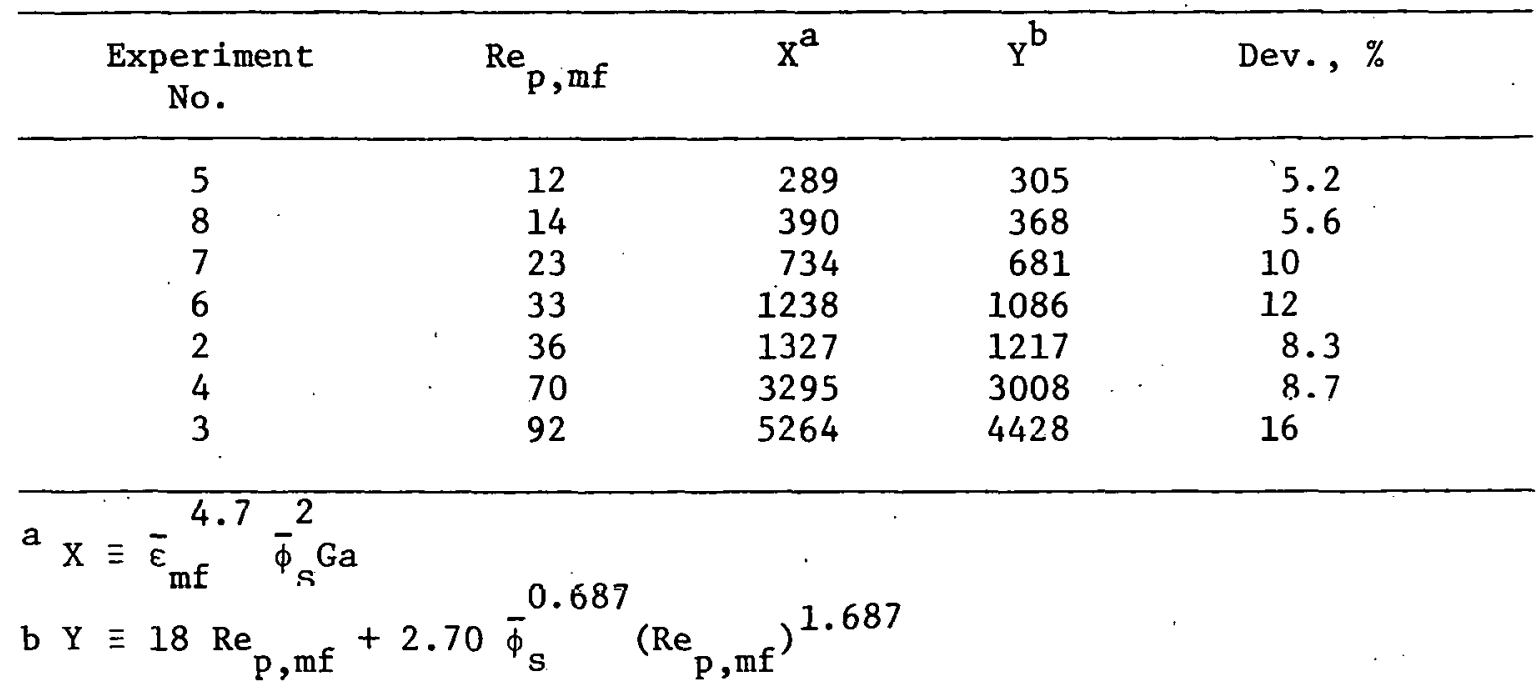

teristics of spherical particles. Here $C_{D}$ is the drag coefficient. For a bed composed of nonspherical particles of a wide size range, Zenz's relations are modified as follows:

$$
\left[\frac{\operatorname{Re} p}{C_{D}}\right]^{1 / 3}=u \frac{4}{3}\left[\frac{\mu\left(\rho_{s}-\rho_{g}\right) g}{\rho_{g}^{2}}\right]^{-1 / 3}
$$

and

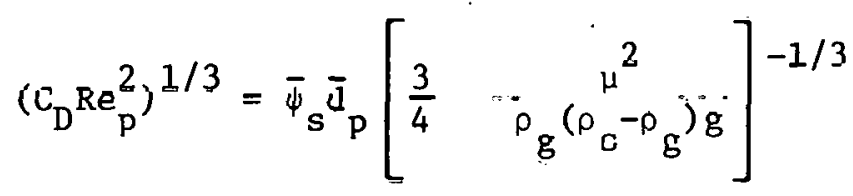

Zenz's procedure is employed here with equation 22 and equation 23 to check whether' the plot of our data, taken at minimum fluidization fur different temperature and pressure conditions of the bed, is consistent with the plots of Zenz. The experimental data (plotted in Fig. 2) pertain to a mean bed voidage of 0.650 . The suggested functional dependence of this plot implies at least qualitative correctness of the theory of drag forces acting on particles at minimum fluidization. This analysis also validates the extension of the procedure suggested by Zenz for spherical particles to nonspherical particles of a wide size range as included in equation 22 and equation 23. Also given in Fig. 2 are the two plots approximately reproduced from the graph given by Zenz and Othmer ${ }^{25}$ for bed voidage values of 0.60 and 0.70 for spherical particles. Zenz and Othmer generated these curves by smoothing the available literature data. Their agreement with our results, as contained in Fig. 2, reflects the consistency of our measured $u_{\mathrm{mf}}$ values and the adopted characterization procedure for nonspherical particles of a wide size range with the literature values of particulate fluidization and sedimentation data on spherical particles. 


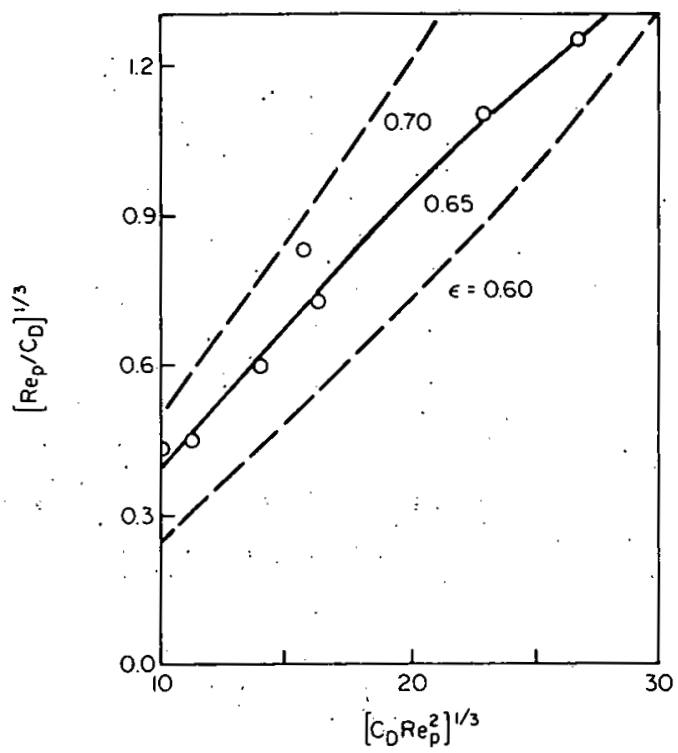

Fig. 2. A correlation plot for particulate fluidization. Circles are our experimental points, and the continuous curve is a smooth plot through them. Broken curves are approximate reproductions from Zenz and Othmer. 25

Andersson 26 developed a modified version of the pressure drop correlation of Ergun by introducing a tortuosity factor, q, a cross section factor, $\mathrm{Z}$, and an inertial drag coefficient, $\mathrm{C}_{i}$. His final result for the particulate fluidized bed composed of uniform size spheres, when modified for the nonspherical particles of a wide size range, becomes

$$
\frac{\Delta P}{L_{m f}}=36 z q^{2} \frac{(1-\bar{\varepsilon})^{2}{ }_{\mu u}{ }_{m f}}{\bar{\varepsilon}^{3}\left(\bar{\phi}_{s} \bar{d}_{p}\right)^{2}}+6 c_{i} q^{3} \frac{(1-\bar{\varepsilon}) p}{\bar{\varepsilon}_{m f}^{3}\left(\bar{\phi}_{s} \bar{d}_{p}{ }^{u_{m f}}\right.}
$$

Here

$$
\mathrm{q}=1.71\left(\frac{1-\bar{\varepsilon}}{\bar{\varepsilon}}\right)^{0.15},
$$

and

$$
c_{i}=4.5 / 8
$$


Calculated values of $\Delta \mathrm{P}$ by use of these expressions agree with the observed values for experiments $2,3,4,6$, and 7 within the percentage deviations of $15,5.6,7.7,16.3$, and 20 , respectively. The experimental values were each greater than the corresponding calculated results. This is regarded as fair agreement since the mean value of sphericity was computed from Ergun correlation at low Reynolds number by using the observed pressure drops. Further, since the correlations of equation 24 through equation 27 are based on data for spherical particles, their validity for our system is only approximate. Nevertheless, the above calculations are revealing and substantiate to a large extent the present approach of employing $\varepsilon, d_{p}$, and $\rho_{s}$ values to describe a bed of a wide size range of nonspherical particles.

Quality of Fluidization

Another important aspect of modeling studies lies in the adequate understanding of the dispersion of solid particles in the gas, i.e., the quality of fluidlzation of the bed. Suitable crlterla fur determining the quality of fluidization have been developed for combining theoretical analysis with experimental data. Thus, Wilhelm and Kwauk ${ }^{27}$ report that at minimum fluidization, the Froude number, defined as

$$
F r_{m f}=u_{m f}^{2} / d_{p} g
$$

is smaller than 0.13 for smooth or particulate fluidization and is greater than 0.13 for bubbling or aggregative fluidization. Richardson 28 puts this Froude number for the transition between particulate and aggregative fluidization as unity. For our experiments, the Froude numbers, computed by means of equation 28 with $\vec{d}_{p}$, range from 7.7 to 18.4. This suggests that, even at minimum fiuidizing condition, the bed as a whole may not be smoothly fluldized and that at least parts of it are in a state of bubbling fluidization. This is further confirmed by applying the criteria of Romero and Johanson, ${ }^{29}$ who suggested that the product of the following four dimensionless groups:

$$
\left.\left(\mathrm{Fr}_{\mathrm{mf}}\right)\left(\operatorname{Re}{ }_{\mathrm{p}, \mathrm{mf}}\right) \cdot\left\{\left(\rho_{\mathrm{s}}-\rho_{\mathrm{g}}\right) / \rho\right)\right\}\left(\mathrm{L}_{\mathrm{mf}} / \mathrm{d}_{\mathrm{t}}\right)
$$

should be smaller than 100 or greater than 100 for a smooth or a bubbling fluidized bed, respectively. For our runs, this product is much larger, about $10^{6}$. In equation $29, d_{t}$ ie the diameter of the reartnr. Although the basis of these criteria is sound, some caution is essential in the quantitative application, because these limlls were. established by experiments on particles of the same size, in many cases with spherical or nearly spherical particles, and in relatively shallow beds.

A logical inference on deep beds of particles of wide size distribution such as those employed in this work is that smooth fluidization occurs at the bottom of the bed, where the pressure is high and gas velocity low, and that bubbling fluidization occurs at lie top, where 
the terminal velocity ${ }^{7}$. for the smallest size particles is twice the superficial gas velocity. As a result, these small particles are not likely to be permanently thrown out of the bed. The pressure drop for a range of fluidizing-gas velocities greater than that required for the bed at minimum fluidization has been observed to be approximately constant; this is consistent with the conjectured quality of fluidization. Because the pressure fluctuations are rather modest, we exclude the possibility that slugging is occurring. Furthermore, in view of the validity of equation 7 , the prospects for channeling or for establishing circulation patterns within the bed are somewhat remote. Although these conclusions clearly follow from the present work and are consistent with the accumulated experience in the literature, they are strictly valid only for particle-size distributions similar to those given in Table 1.

\section{CONCLUSIONS}

The measurement of minimum fluidization velocity of a dolomite bed consisting of particles in the range of about 1410-88 $\mu \mathrm{m}$. and their analytical interpretation leads to the following conclusions:

(1) At a given temperature, the minimum fluidization velocities decrease with increasing pressure and at a given pressure these are independent of temperature. This inference is based on experiments performed in the temperature range of $70-800^{\circ} \mathrm{F}$ and pressure range of 26-121 psia.

(2) The experimentally determined minimum fluidizing air velocities are adequately correlated by the Ergun relation if appropriate values for the mean particle diameter and mean sphericity for the solid particles are used.

(3) The criteria developed to determine the quality of fluidization of a bed composed of particles of single size need revision for their application to a bed consisting of particles of wide size distribution.

(4) The correlations developed by Wen and $\mathrm{Yu}^{14}$ and $\mathrm{Zenz}^{24}$ are found to be adequate in predicting minimum fluidizing velocities for a bed of wide size range particles.

\section{ACKNOWLEDGMENTS}

The support of this program by the National Science Foundation and the Energy Research and Development Agency is gratefully acknowledged. This study was made under the direction of Messrs. A. A. Jonke, $D$. Webster, and L. Burris of the Chemical Engineering Division. Experimental data wcre obtained by Messirs. C. Schoffscoll, G. 'leats, and J. Stockbar. 


\section{REFERENCES}

1. S. Ergun, Chem. Eng. Prog. 48, 89-94, 1952.

2. P. C. Carman, Trans. Inst. Chem. Eng. 15, 150-66, 1937.

3. T. H. Chilton and A. P. Colburn, Trans. Am. Inst. Chem. Eng. 26, $178-96,1931$.

4. M. Leva, Chem. Eng. Prog. 43, 549-554, 1974.

5. M. Leva and M. Grummer, Chem. Eng. Prog. 43, 633-38, 713-18, 1947.

6. S. Ergun and A. A. Orning, Ind. Eng. Chem. 41, 1179-84, 1949.

7. D. Kunii and 0 . Levenspiel, Fluidization Englneering, Ch. 3, John Wiley \& Sons, Inc., New York, 1969.

8. L. E. Brownel1 and D. L. Katz, Chem. Eng. Prog. 43, 537-48, 1947.

9. R. D. Morse, Ind. Eng. Chem. 41, 1117-24, 1949.

10. M. Leva, Fluidization, Chapter 3, p. 62, McGraw-Hill Book Co., Inc., New York, 1959.

11. J. F. Frantz, Chem. Eng. 69, 161-78, 1962 .

12. G. Narsimhan, Am. Inst. Chem. Eng. J. 11, 550-4, 1965.

13. J. F. Frantz, Chem. Eng. Prog. Sym. Series 62, No. 62, 21-31, 1966.

14. C. Y. Wen and Y. H. Yu, Chem. Eng. Prog. Sym. Serles 62, No. 62, $100-11,1,966$.

15. C. Y. Wen and Y. H. Yu, Am. Inst. Chem. Eng. J. 12, 610-12, 1966.

16. J. F. Davidson and D. Harrison, Fluidized Particles, p. 14, Cambridge University Press, London, 1963.

17. L. Davies and J. F. Richardson, Trane. Inst. Chem. Eng. 44, 'I'293T-305, 1966 .

18. T. Mii, K. Yoshida, and D. Kunii, J. Chem. Eng. Japan 6, 100-2, 1972.

19. B. Singh, G. R. Rigby, and T. G. Callcott, Trans. Inst. Chem. Eng. 51, $93-6,1973$.

20. J. Broughton, Trans. Inst. Chem. Eng. 52, 105-7, 1974. 
21. Reference 10, p. 64 , equation 3-24.

22. R. G. Kunz, Powder Technol. 4, 156-62, 1970-71.

23. R. E. Hicks, Ind. Eng. Chem. Fundam. $9,500-2,1970$.

24. F. A. Zenz, Petrol. Refiner 36, 147-55, 1957 .

25. F. A. Zenz and D. F. Othmer, Fluidization and Fluid-Particle Systems, Reinhold Publishing Corporation, New York, Chapter 7, 1960 .

26. K. E. Bertil Andersson, Chem. Eng. Sci. 15, 276-97, 1971.

27. R. H. Wilhelm and M. Kwauk, Chem. Eng. Prog. 44, 201-18, 1948.

28. J. R. Richardson, Fluidization, Chapter 2, P. 26, J. F. Davidson and D. Harrison, Eds., Academic Press, New York, 1971.

29. J. B. Romero and L. N. Johanson, Chem. Eng. Prog. Sym. Series 58(38), 28-37, 1962 . 